\title{
Organic food consumption during pregnancy and its association with health-related characteristics: the KOALA Birth Cohort Study
}

\author{
Ana Paula Simões-Wüst ${ }^{1,2, *}$, Carolina Moltó-Puigmartí ${ }^{3}$, Eugene HJM Jansen ${ }^{4}$, \\ Martien CJM van Dongen ${ }^{3}$, Pieter C Dagnelie ${ }^{3,5}$ and Carel Thij ${ }^{3}$ \\ ${ }^{1}$ Research Department, Clinic Arlesheim, Arlesheim, Switzerland: ${ }^{2}$ Department of Obstetrics, Perinatal \\ Pharmacology, Zurich University Hospital, Schmelzbergstrasse 12/PF 125, Path G 51 a, 8091 Zurich, Switzerland: \\ ${ }^{3}$ Maastricht University, Department of Epidemiology, CAPHRI School for Public Health and Primary Care, Maastricht, \\ The Netherlands: ${ }^{4}$ Centre for Health Protection, National Institute for Public Health and the Environment, Bilthoven, \\ The Netherlands: ${ }^{5}$ Maastricht University, CARIM School for Cardiovascular Disease, Maastricht, The Netherlands
}

Submitted 21 December 2016: Final revision received 11 May 2017: Accepted 15 May 2017: First published online 19 June 2017

\begin{abstract}
Objective: To investigate the associations of organic food consumption with maternal pre-pregnancy BMI, hypertension and diabetes in pregnancy, and several blood biomarkers of pregnant women.

Design: Prospective cohort study.

Setting: Pregnant women were recruited at midwives' practices and through channels related to consumption of food from organic origin.

Subjects: Pregnant women who filled in FFQ and donated a blood sample ( $n$ 1339). Participant groups were defined based on the share of consumed organic products; to discriminate between effects of food origin and food patterns, healthy diet indicators were considered in some statistical models.

Results: Consumption of organic food was associated with a more favourable pre-pregnancy BMI and lower prevalence of gestational diabetes. Compared with participants consuming no organic food (reference group), a marker of dairy products intake (pentadecanoic acid) and trans-fatty acids from natural origin (vaccenic and rumenic acids) were higher among participants consuming organic food (organic groups), whereas elaidic acid, a marker of the intake of trans-fatty acids found in industrially hydrogenated fats, was lower. Plasma levels of homocysteine and 25-hydroxyvitamin D were lower in the organic groups than in the reference group. Differences in pentadecanoic acid, vaccenic acid and vitamin D retained statistical significance when correcting for indicators of the healthy diet pattern associated with the consumption of organic food.

Conclusions: Consumption of organic food during pregnancy is associated with several health-related characteristics and blood biomarkers. Part of the observed associations is explained by food patterns accompanying the consumption of organic food.
\end{abstract}

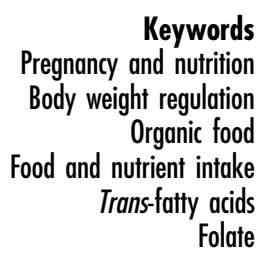

During the last decades, consumption of organic food (for a definition see IFOAM Organics International ${ }^{(1)}$ ) has increased worldwide. In the EU, between 2005 and 2011, there was a $50 \%$ increase in organic farming accompanied by a considerable growth in sales of organic products on the internal food market ${ }^{(2)}$. However, the prices of organic food are in general higher than those of conventionally produced food. Consumers' motivation to pay higher prices for organic food relies in part on environmental concerns, but also on the conviction that consumption of organic food might promote health ${ }^{(3)}$. During pregnancy, health-related concerns become particularly relevant.
Therefore, pregnant women might be especially motivated to consume organic food.

Within the KOALA Birth Cohort Study (Dutch acronym for 'Child, parents, and health: addressing lifestyle and constitution'), it has been shown that levels of the major conjugated linoleic acid (CLA) isomer, rumenic acid (RA), and of its corresponding precursor trans-vaccenic acid (VA), were higher in the milk of mothers who consumed organic dairy and ruminant meat products compared with mothers with a conventional diet ${ }^{(4)}$. Higher levels of these ruminant fatty acids in mother's milk, in turn, were shown to be associated with better atopic outcomes in their 
breast-fed children ${ }^{(5)}$. Moreover, 2-year-old children consuming milk products almost exclusively from organic origin had a significantly lower risk to develop eczema compared with children consuming conventional milk products ${ }^{(6)}$. Despite this evidence and that from some other promising studies ${ }^{(7,8)}$, more research is warranted on possible health-related effects of organic food consumption, especially in pregnant women. Interestingly, we recently showed that the pregnant women in the KOALA study using food from organic production exhibit specific sociodemographic and behavioural characteristics when compared with those who consume food of conventional production only ${ }^{(9)}$.

Furthermore, consumption of organic food was associated with intake of more products of vegetable origin (soya/vegetarian products, vegetables, cereal products, bread, fruits, and legumes) and fewer animal products (milk and meat), sugar and potatoes than consumed in conventional diets. This translated into healthier food patterns in the organic groups, which could be confirmed by a principal component analysis of the consumed food items. Within the Norwegian cohort study MoBa, a principal component analysis has been done with similar results ${ }^{(10)}$. A food pattern with more vegetable food products and less sweet and alcoholic beverages, processed meat and milk was also seen in the NutriNet-Santé study ${ }^{(11)}$, while the German National Nutrition Survey II revealed that persons who followed an organic diet also consumed more fruits and vegetables and less meat/sausages and soft drinks ${ }^{(12)}$. Taken together, these studies indicate that the associations between consumption of organic food and healthier food patterns must be considered when studying the influence of organic food consumption on health-related characteristics. Considering this, in the present work we investigated the associations of organic food consumption with maternal pre-pregnancy BMI, hypertension and diabetes in pregnancy, and several blood biomarkers of pregnant women, and assessed whether such associations may be related to the women's food patterns ${ }^{(9)}$.

\section{Participants and methods}

\section{Study design and participants}

The KOALA Birth Cohort Study is a prospective cohort study of mother-infant pairs in the Netherlands, which was approved by the Medical Ethical Committee of Maastricht University/Academic Hospital Maastricht (MUMC+). All children's parents signed for written informed consent. KOALA is the acronym (in Dutch) for 'Kind, Ouders en gezondheid: Aandacht voor Leefstijl en Aanleg' (Child, parents and health: addressing lifestyle and constitution).

From October 2000 until December 2002, 2343 pregnant women participating in an ongoing prospective cohort study on Pregnancy-Related Pelvic Girdle Pain (PPGP) were recruited at midwife practices in the southern part of the Netherlands ${ }^{(13,14)}$. This number represents $33.4 \%$ of the 7020 participating in the PPGP study. The PPGP study did not use lifestyle-related inclusion criteria and previous work has shown the participants to be comparable to the general population ('general population recruitment group') ${ }^{(13)}$. To enrich the KOALA study with women adhering to an alternative lifestyle, the study was advertised through several specific channels, such as organic food shops, anthroposophic general practitioners and midwives, under-five clinics, Rudolf Steiner schools and relevant magazines. Women interested in participating were recruited from January 2002 until December 2002 without additional selection ('alternative lifestyle recruitment group', $n$ 491). Therefore, a total of 2834 women were recruited in the KOALA study (i.e. 2343 from the general population recruitment group and 491 from the alternative lifestyle recruitment group). A possible selective participation of PPGP women in the KOALA study was evaluated using a short questionnaire that allowed comparison of: (i) PPGP participants who did not participate in the KOALA study; (ii) PPGP participants who accepted to participate in the KOALA study; and (iii) KOALA participants from the alternative lifestyle recruitment group ${ }^{(14)}$. The results showed that the two former groups are comparable with each other and clearly different from the latter in terms of prevalence of dietary habits deviating from standard as defined by including organic food and/or being vegetarian or macrobiotic $(4.2,6.5$ and $73.4 \%$, respectively).

All women were enrolled in the KOALA study between 14 and 18 weeks of gestation and received detailed questionnaires on sociodemographic and health characteristics at the time of recruitment and at 30 weeks of pregnancy. At 34 weeks of pregnancy, an additional questionnaire, dealing with lifestyle habits and focusing mainly on dietary habits (FFQ), was sent to the women. In all women recruited in both groups from January 2002 onwards, blood samples were collected around week 36 of pregnancy ( $n 1355$ out of 2834 recruited in the KOALA study, $47 \cdot 8 \%$ ). For the present analysis, data from both questionnaires, from the FFQ and from the blood analysis were needed. These data were available for 1346 (99.3\%) of the 1355 women who had provided a blood sample. To enhance comparability with our previous work ${ }^{(9)}$, mothers of children who were stillborn or died as neonates $(n 3)$ or who had Down's syndrome ( $n$ 4) were excluded. The analyses presented here were therefore performed with 1339 women out of the 2834 initially recruited in the KOALA study, $47 \cdot 2 \%$ ). Seventy-two per cent thereof originated from the general population recruitment group $(965 / 1339,72 \cdot 1 \%)$, with the remaining ones $(374 / 1339$, $27.9 \%$ ) having been recruited from the alternative lifestyle recruitment group. All maternal data used in the KOALA study were self-reported, except for information on hypertension in pregnancy or gestational diabetes, which was extracted from midwives' reports. 


\section{Organic groups' definition}

Among other items, the 34-week questionnaire included: (i) items on adherence to ideological or religious rules, including vegetarianism, veganism and anthroposophy; (ii) a 198-item FFQ; and (iii) questions on the origin (organic, conventional or other food-specific possibilities) of seven food groups: meat, eggs, vegetables, fruit, milk and milk products, bread, and dried food products (dried legumes and cereals), as well as on the percentage of organic origin of purchases of each food group: not at all, less than $50 \%$, between $50 \%$ and $90 \%$ or more than $90 \%$. The 198-item FFQ was an extended version of a previously existing, validated $\mathrm{FFQ}^{(15)}$. Relative to the original FFQ, the extended version comprised several additional items that can be expected to be more often consumed by people with alternative lifestyles.

The level of organic food use was defined based on the questions concerning origin of most of the consumed items and the percentage of organic products of all seven food groups taken together, unless the respondents had reported not to consume at least one of these groups. In this case, only the consumed food groups were considered for the definition of organic food use. The following three groups of organic food purchase were defined: (i) ' $<50 \%$ organic' ( $n$ 441), if some food groups were of organic production, but not all were reported as being more than $50 \%$ organic; (ii) '50-90\% organic' ( $n$ 73), if $50 \%$ of all consumed food groups was of organic production but not all $>90 \%$; and (iii) ' $>90 \%$ organic' ( $n$ 58), if more than $90 \%$ of all consumed food groups was of organic production. As a reference group for these three organic groups, we used the fourth group of participants, namely those who purchased all consumed food groups of conventional origin ('conventional' group, $n$ 767).

\section{Choice of biomarkers}

Biomarkers considered of public health relevance for pregnant women at the time the KOALA mothers were pregnant (years 2000 to 2002) were analysed: Fe, homocysteine, 25-hydroxyvitamin D (25(OH)D), plasma lipids (including TAG, total cholesterol, HDL cholesterol and fatty acids). This analytical work was commissioned by the Dutch Ministry of Health to the National Institute of Public Health and the Environment.

\section{Blood collection and analysis}

Maternal blood was collected in EDTA-tubes at 34-36 weeks of pregnancy. After centrifugation, the EDTA-plasma was stored in cryovials at $-80^{\circ} \mathrm{C}$. Laboratory measurements were done at the Laboratory for Toxicology and Nutrition, National Institute of Public Health and the Environment (Bilthoven, the Netherlands). The kits for quantification of TAG, total cholesterol and HDL cholesterol were from Beckman Coulter (Mijdrecht, the Netherlands; numbers 445850, 467825 and 650207, respectively).
The measurements of TAG, total cholesterol, HDL cholesterol and homocysteine were performed on an autoanalyser (LX20 Pro; Beckman Coulter). Maternal fatty acid status was assessed in plasma phospholipids, after removing the plasma proteins by precipitation and centrifugation. Fatty acid methyl esters were obtained according to a standardised protocol wherein the sample was extracted and subsequently hydrolysed and methylated with boron trifluoride. Hexane was added to extract the fatty acid methyl esters, and these were separated using a GC-3900 gas chromatograph (Varian Inc., Middelburg, the Netherlands) equipped with a CP 8400 auto injector. Galaxie software was used for quantification and identification of peaks. Fatty acid concentrations are expressed as proportions of total fatty acids (C14-C22) present in the chromatogram (weight percentage, wt $\%$ ). Plasma ferritin was measured with an immunoanalyser (Access-2; Beckman Coulter) using a Quantex kit (Ferritin 3000-2271; Biokit SA, Barcelona, Spain). This method has a lowest detection limit of $6 \mathrm{mg} / 1 ; 141$ samples were below this threshold, in which cases a value of $3 \mu \mathrm{g} / \mathrm{l}$ was imputed. The kit for quantification of homocysteine (number 905510) was from Dialab, Vienna, Austria. Plasma levels of $25(\mathrm{OH}) \mathrm{D}$ were determined with the OCTEIA 25-Hydroxy Vitamin D ELISA kit from Immuno Diagnostic Systems (Boldon, UK).

For each biomarker, the following inter-assay variation values at the various levels were obtained: (i) TAG, 3.0\% at $0.80 \mathrm{mmol} / 1,2.7 \%$ at $1.25 \mathrm{mmol} / \mathrm{l}$ and $2.5 \%$ at $1.73 \mathrm{mmol} / \mathrm{l}$; (ii) total cholesterol, $2 \cdot 8 \%$ at $2 \cdot 6 \mathrm{mmol} / 1,3.2 \%$ at $4.4 \mathrm{mmol} / 1$ and $2.7 \%$ at $6.0 \mathrm{mmol} / \mathrm{l}$; (iii) HDL cholesterol, $4.8 \%$ at $0.73 \mathrm{mmol} / 1,5.4 \%$ at $1.21 \mathrm{mmol} / \mathrm{l}$ and $5.2 \%$ at $1.71 \mathrm{mmol} / \mathrm{l}$; (iv) fatty acids, $14.9 \%$ for the fatty acids at $0 \cdot 1-0.5 \%, 11 \cdot 8 \%$ at $0.5-2.0 \%$ and $2.0 \%$ at $>2.0 \%$; (v) ferritin, $3.8 \%$ at $61.1 \mathrm{ng} / \mathrm{ml}$ and $3.0 \%$ at $277 \mathrm{ng} / \mathrm{ml}$; (vi) homocysteine, $6.9 \%$ at $6.8 \mu \mathrm{mol} / 1,5.7 \%$ at $12.1 \mu \mathrm{mol} / 1,2 \cdot 8 \%$ at $28.9 \mu \mathrm{mol} / 1$ and $3.7 \%$ at of $39.1 \mu \mathrm{mol} / \mathrm{l}$; and (vii) $25(\mathrm{OH}) \mathrm{D}, 7.5 \%$ at $21.7 \mathrm{nmol} / 1$ and $5.8 \%$ at $84.6 \mathrm{nmol} / 1$.

\section{Statistical methods}

The various participant groups were descriptively characterised in terms of sociodemographic and lifestyle characteristics (data shown in Tables 1 and 2). Unless indicated otherwise, data were expressed as mean and SD. Differences in values for numerical variables (e.g. BMI, biomarkers) between the various organic groups and the reference group were evaluated using linear regression with dummy coding for level of organic food use, using an index variable coded 1 to 4 for the conventional (reference), $<50 \%$, $50-90 \%$ and $>90 \%$ organic groups, respectively, in the linear regression. For categorical health-related variables, the trend of increasing (or decreasing) proportions over the above four dietary groups was tested by Kendall's $\tau_{\mathrm{c}}$.

For each biomarker, a multivariable linear regression model was defined in which the following covariables were 
adjusted for: maternal parity and age (in all analyses) and season when the questionnaire was filled in (only for dietary markers expected to differ by season, such as the ruminant fatty acids RA and $\mathrm{VA}^{(16)}$ and vitamin $\left.\mathrm{D}^{(17)}\right)$. Moreover, for long-chain fatty acids, ferritin, homocysteine and $25(\mathrm{OH}) \mathrm{D}$, we adjusted for supplement use of long-chain fatty acids, Fe, vitamin $\mathrm{B}_{12}$ and vitamin $\mathrm{D}$, respectively.

To discriminate between possible effects of food origin (from conventional or organic production) $v$. those of the (more or less healthy) food patterns, an additional model was developed for each biomarker, in which two indicators of a healthy diet were added as covariables. These indicators consist of the scores corresponding to the two components with the highest eigenvalues determined in a principal component analysis performed with FFQ data (see our previous work ${ }^{(9)}$ ). These were clearly dominating in the scree plot, accounted for $6 \cdot 1 \%$ of the variance in food intake, and the corresponding scores were significantly higher or lower in all organic groups than in the conventional (reference) group. They were named 'alternative/vegetarian' and 'fast food', respectively, and can be seen as indicative of how healthy a diet is ${ }^{(9)}$. Together, they are comparable to the 'health and sustainability' component previously detected in the MoBa study, which is close to the dietary recommendations for health as well as ecological sustainability ${ }^{(10)}$.

All data were analysed with the statistical software package IBM ${ }^{\circledR}$ SPSS $^{\circledR}$ Statistics Version 19.0 and two-tailed $P$ values $<0.05$ were considered statistically significant.

\section{Results}

\section{Sociodemographic characteristics}

Mothers in the organic groups had a higher education level, were older at delivery and had more often delivered at least one child previously (Table 1 ). The large majority of women of all four groups were of Dutch ancestry. According to the recruitment methods (see 'Study design and participants' section), relatively more women with a fully conventional diet lived in southern provinces (Limburg and Brabant) and relatively more women among the organic groups lived in the mid-northern provinces (Gelderland, Utrecht and others).

\section{Associations between organic food consumption and bealth-related characteristics}

As expected from the recruitment methods, more women in the organic groups adhered to living rules related to alternative lifestyles such as vegetarianism and anthroposophy (Table 2). No significant differences were found with regard to alcohol consumption or active smoking. However, the percentage of women who were exposed to passive smoke at 34 weeks of pregnancy was lower in the organic groups than in women consuming exclusively conventional food. In the organic food groups, the average pre-pregnancy BMI was significantly lower than in the conventional (reference) group (Table 2), with a clear difference already noticeable in the $<50 \%$ organic group (mean BMI 22.9 (SD 3.36) $v .23 .8$ (sD 3.92$) \mathrm{kg} / \mathrm{m}^{2}$ in the conventional group, $\left.P<0.001\right)$.

Table 1 Baseline sociodemographic characteristics of the pregnant women with varying purchases of food of organic $v$. conventional origin, KOALA Birth Cohort Study, The Netherlands, 2000-2002 ( $n$ 1339)

\begin{tabular}{|c|c|c|c|c|c|c|c|c|}
\hline \multirow[b]{2}{*}{ Characteristic } & \multicolumn{2}{|c|}{$\begin{array}{l}\text { Conventional (reference) } \\
\qquad(n 767)\end{array}$} & \multicolumn{2}{|c|}{$\begin{array}{l}<50 \% \text { organic } \\
(n 441)\end{array}$} & \multicolumn{2}{|c|}{$\begin{array}{l}50-90 \% \text { organic } \\
(n 73)\end{array}$} & \multicolumn{2}{|c|}{$\begin{array}{l}>90 \% \text { organic } \\
(n 58)\end{array}$} \\
\hline & Mean or \% & sD or $n$ & Mean or \% & SD or $n$ & Mean or \% & SD or $n$ & Mean or \% & sD or $n$ \\
\hline $\begin{array}{l}\text { Age of the mother at delivery } \\
\text { (years), mean and SD }\end{array}$ & $32 \cdot 0$ & 3.60 & $32 \cdot 9$ & 3.91 & $34 \cdot 1$ & $4 \cdot 17$ & $32 \cdot 5$ & 3.85 \\
\hline \multicolumn{9}{|l|}{ Number of previous children } \\
\hline 0 & $43 \cdot 7$ & 335 & $40 \cdot 8$ & 179 & $28 \cdot 8$ & 21 & $41 \cdot 4$ & 24 \\
\hline 1 & $42 \cdot 5$ & 326 & $41 \cdot 3$ & 182 & $45 \cdot 2$ & 33 & $39 \cdot 7$ & 12 \\
\hline 2 or more & $13 \cdot 8$ & 106 & $17 \cdot 7$ & 80 & $26 \cdot 0$ & 19 & $18 \cdot 9$ & 11 \\
\hline \multicolumn{9}{|l|}{ Highest level of education } \\
\hline Lower or lower-middle (vocational) & $8 \cdot 4$ & 64 & $5 \cdot 4$ & 24 & $11 \cdot 0$ & 8 & $5 \cdot 2$ & 3 \\
\hline Mid-higher (vocational) & 38.5 & 295 & $30 \cdot 4$ & 134 & 20.5 & 15 & $27 \cdot 6$ & 16 \\
\hline Higher (high vocational or academic) & $49 \cdot 7$ & 381 & 59.9 & 264 & $63 \cdot 0$ & 46 & $63 \cdot 8$ & 37 \\
\hline Others & 3.5 & 27 & $4 \cdot 3$ & 19 & $5 \cdot 5$ & 4 & 3.4 & 2 \\
\hline Mother born in the Netherlands & $97 \cdot 8$ & 743 & 94.6 & 417 & 94.5 & 69 & $93 \cdot 1$ & 54 \\
\hline \multicolumn{9}{|l|}{ Living area (province) } \\
\hline South (Limburg) & $41 \cdot 1$ & 315 & $29 \cdot 7$ & 131 & $17 \cdot 8$ & 13 & $17 \cdot 2$ & 10 \\
\hline Mid-south (Brabant) & $37 \cdot 7$ & 289 & $25 \cdot 9$ & 114 & $24 \cdot 7$ & 18 & $20 \cdot 7$ & 12 \\
\hline $\begin{array}{l}\text { Mid-east and mid-north } \\
\text { (Gelderland, Utrecht and other provinces) }\end{array}$ & $21 \cdot 3$ & 162 & $44 \cdot 2$ & 195 & $57 \cdot 6$ & 42 & $61 \cdot 8$ & 36 \\
\hline \multicolumn{9}{|l|}{ Season when FFQ was filled out* } \\
\hline Spring & $19 \cdot 9$ & 153 & $18 \cdot 6$ & 82 & $17 \cdot 8$ & 13 & $20 \cdot 7$ & 12 \\
\hline Summer & $20 \cdot 5$ & 157 & $25 \cdot 6$ & 113 & 21.9 & 16 & 31.0 & 18 \\
\hline Autumn & $26 \cdot 5$ & 203 & 28.6 & 126 & $30 \cdot 1$ & 22 & $24 \cdot 1$ & 14 \\
\hline Winter & $33 \cdot 1$ & 254 & $27 \cdot 2$ & 120 & $30 \cdot 1$ & 22 & $24 \cdot 1$ & 14 \\
\hline
\end{tabular}

Data are presented as $\%$ and $n$, unless indicated otherwise.

Missing data: for mother born in the Netherlands, $n 1$ in the conventional group; for living area (province), $n 1$ in the $<50 \%$ organic group.

*Spring, 1 March-31 May; summer, 1 June-31 August; autumn, 1 September-30 November; winter, 1 December-end February. Blood sampling occurred two weeks after filling out the FFQ. 
Table 2 Lifestyle and health-related characteristics of pregnant women with varying purchases of food of organic $v$. conventional origin, KOALA Birth Cohort Study, The Netherlands, 2000-2002 ( $n$ 1339)

\begin{tabular}{|c|c|c|c|c|c|c|c|c|}
\hline \multirow[b]{2}{*}{ Characteristic } & \multicolumn{2}{|c|}{$\begin{array}{c}\text { Conventional (reference) } \\
(n \text { 767) }\end{array}$} & \multicolumn{2}{|c|}{$\begin{array}{l}<50 \% \text { organic } \\
\quad(n 441)\end{array}$} & \multicolumn{2}{|c|}{$\begin{array}{c}50-90 \% \text { organic } \\
(n 73)\end{array}$} & \multicolumn{2}{|c|}{$\begin{array}{l}>90 \% \text { organic } \\
(n 58)\end{array}$} \\
\hline & $\%$ or mean & $n$ or SD & $\%$ or mean & $n$ or SD & $\%$ or mean & $n$ or SD & $\%$ or mean & $n$ or SD \\
\hline \multicolumn{9}{|l|}{ Lifestyle characteristics } \\
\hline Alternative group & $10 \cdot 2$ & 78 & $47 \cdot 6$ & 210 & 68.5 & 50 & $56 \cdot 9$ & 36 \\
\hline Adheres to living rules & $1 \cdot 7$ & 13 & $16 \cdot 6$ & 72 & $32 \cdot 4$ & 23 & 43.1 & 25 \\
\hline Identifies with anthroposophy & 0.4 & 3 & $6 \cdot 3$ & 28 & 13.7 & 10 & $19 \cdot 0$ & 11 \\
\hline Vegetarianism & 1.4 & 11 & 8.8 & 39 & $17 \cdot 8$ & 13 & $24 \cdot 1$ & 14 \\
\hline Veganism & 0.1 & 1 & 0.0 & 0 & 0.0 & 0 & 0.0 & 0 \\
\hline \multicolumn{9}{|l|}{ Alcohol consumption during pregnancy (glasses/d) } \\
\hline 0 & 81.9 & 628 & $80 \cdot 5$ & 355 & 79.5 & 58 & 84.5 & 49 \\
\hline 1 & 11.0 & 84 & 11.8 & 52 & $12 \cdot 3$ & 9 & 6.9 & 4 \\
\hline 2 & $4 \cdot 3$ & 33 & 3.6 & 16 & 5.5 & 4 & $5 \cdot 2$ & 3 \\
\hline 3 & 1.3 & 10 & 1.8 & 8 & 0.0 & 0 & 1.7 & 1 \\
\hline 4 or more & 1.6 & 12 & $2 \cdot 3$ & 10 & $2 \cdot 7$ & 2 & 1.7 & 1 \\
\hline \multicolumn{9}{|c|}{ Active maternal smoking during pregnancy (cigarettes/d) } \\
\hline 0 & 93.7 & 719 & $96 \cdot 6$ & 426 & 93.2 & 68 & $96 \cdot 6$ & 56 \\
\hline $1-5$ & $2 \cdot 1$ & 16 & $2 \cdot 0$ & 9 & $2 \cdot 7$ & 2 & 0.0 & 0 \\
\hline $6-10$ & 3.0 & 23 & 0.7 & 3 & $4 \cdot 1$ & 3 & 1.7 & 1 \\
\hline $11-15$ & 0.8 & 6 & 0.7 & 3 & 0.0 & 0 & $1 \cdot 7$ & 1 \\
\hline $16-20$ & 0.4 & 3 & 0.0 & 0 & 0.0 & 0 & 0.0 & 0 \\
\hline \multicolumn{9}{|l|}{ Passive maternal smoking during pregnancy } \\
\hline Rare, $<1 \mathrm{~h} /$ week & $66 \cdot 2$ & 505 & $76 \cdot 7$ & 335 & $80 \cdot 6$ & 56 & $86 \cdot 2$ & 50 \\
\hline Occasionally, but $<1 \mathrm{~h} / \mathrm{d}$ & 23.5 & 179 & $18 \cdot 1$ & 79 & 21.5 & 9 & $6 \cdot 9$ & 4 \\
\hline On average, $1-4 \mathrm{~h} / \mathrm{d}$ & 8.0 & 61 & $4 \cdot 3$ & 19 & 6.9 & 5 & 6.9 & 4 \\
\hline On average, $>4 \mathrm{~h} / \mathrm{d}$ & $2 \cdot 4$ & 18 & 0.9 & 4 & 0.0 & 0 & 0.0 & 0 \\
\hline \multicolumn{9}{|l|}{ Health-related outcomes } \\
\hline Height $(\mathrm{cm})$, mean and SD & 169.9 & $6 \cdot 22$ & $170 \cdot 0$ & $6 \cdot 68$ & $170 \cdot 0$ & 6.06 & 169.5 & 6.48 \\
\hline BMI before pregnancy $\left(\mathrm{kg} / \mathrm{m}^{2}\right) \dagger$, mean and SD & 23.8 & 3.92 & $22 \cdot 9$ & 3.36 & $22 \cdot 5$ & 3.80 & $22 \cdot 6$ & 3.32 \\
\hline Underweight $\left(<18.5 \mathrm{~kg} / \mathrm{m}^{2}\right) \ddagger$ & 3.4 & 26 & 2.5 & 11 & $2 \cdot 7$ & 2 & 1.7 & 1 \\
\hline Normal $\left(18.5-24.9 \mathrm{~kg} / \mathrm{m}^{2}\right) \ddagger$ & $67 \cdot 3$ & 514 & $76 \cdot 8$ & 337 & $80 \cdot 8$ & $5 \overline{9}$ & $77 \cdot 6$ & 45 \\
\hline Overweight $\left(25.0-29.9 \mathrm{~kg} / \mathrm{m}^{2}\right) \ddagger$ & $20 \cdot 9$ & 160 & $15 \cdot 7$ & 69 & $11 \cdot 0$ & 8 & $17 \cdot 2$ & 10 \\
\hline Obesity $\left(\geq 30 \mathrm{~kg} / \mathrm{m}^{2}\right) \ddagger$ & 8.4 & 54 & $5 \cdot 0$ & 22 & 5.5 & 4 & 3.4 & 2 \\
\hline Hypertension in pregnancy & 4.3 & 33 & 3.9 & 17 & 1.4 & 1 & 3.4 & 2 \\
\hline Diabetes in pregnancy§ & $2 \cdot 0$ & 15 & 0.5 & 2 & 0.0 & 0 & 0.0 & 0 \\
\hline
\end{tabular}

Data are presented as $\%$ and $n$, unless indicated otherwise.

Missing data: for adheres to living rules, $n 2, n 7, n 2$ and $n 0$ in the conventional, $<50 \%$ organic, $50-90 \%$ organic and $>90 \%$ organic group, respectively; for height, $n 1$ in the conventional group; for BMI before pregnancy, $n 3$ and $n 2$ in the conventional and $<50 \%$ organic group, respectively; for hypertension, $n 3$ in the conventional group; for diabetes, $n 2$ in the conventional group.

$\dagger P<0.001$ before and after adjustment for maternal age, parity, alcohol consumption and smoking; to calculate statistical significance, linear regression was used with dummy variables indicating the comparison of each organic group with the conventional (reference) group, and the trend over the groups was tested using an index variable coded 1 to 4 for the conventional (reference) group and the $<50 \%, 50-90 \%$ and $>90 \%$ organic groups, respectively, in the linear regression. $\ddagger P<0.001$ considering all four groups defined according to BMI values; to test the trend of increasing or decreasing percentages over the groups, Kendall's $\tau_{\mathrm{c}}$ for categorical variables was applied, with the groups coded 1 to 4 (as mentioned under $\dagger$ ).

$\S P=0.002$ (as in $\ddagger$ ).

In all groups, most women showed a BMI within the normal range $\left(18.5-24.9 \mathrm{~kg} / \mathrm{m}^{2}\right)$, but there was a higher proportion of women with a normal BMI in the organic groups than in the conventional (reference) group.

The occurrence of hypertension did not seem to differ among the groups. However, in the organic groups, fewer participants suffered from diabetes in pregnancy than in the conventional (reference) group. Well-known risk factors for CVD such as alcohol consumption, smoking (see Table 2) and $\mathrm{Na}$ consumption (data not shown) were comparable in the various groups. Moreover, adjusting for smoking and alcohol did not affect the results.

\section{Association between organic food consumption and biomarkers}

While total cholesterol and HDL cholesterol were not significantly different among the groups, LDL cholesterol was significantly higher in the organic groups. The levels of several individual fatty acids also varied among the different groups. On the one hand, the levels of pentadecanoic acid (15:0), VA (18:1n-7,trans), linoleic acid (LA; $18: 2 n-6$, cis $)$ and RA (18:2n-7,trans,n-9,cis) were significantly higher in some organic groups relative to the conventional (reference) group. On the other hand, the levels of elaidic acid (EA; $18: 1 n$-9,trans), $\alpha$-linolenic acid (ALA; 18:3n-3) and arachidonic acid (AA; $20: 4 n$-6) were significantly lower in the organic groups compared with the conventional one. The levels of DHA (22:6n-3) appeared to be lower in the organic groups; the trend over the groups attained statistical significance only when the covariates were considered. Relative to the conventional (reference) group, the organic groups had a markedly lower EA:VA (18:1n-9,trans:18:1n-7,trans), a marker of industrial $v$. natural origin of dietary trans-fatty acids (Table 3). 
Compared with the conventional (reference) group, the blood level of ferritin (Table 3) was lower in the $<50 \%$ and $50-90 \%$ organic groups but higher in the $>90 \%$ organic group. Homocysteine was significantly lower in the $<50 \%$ and $50-90 \%$ organic groups; the test for trend over the groups was significant in the crude model but lost significance when adjusting for maternal age, parity (numerical) and vitamin $\mathrm{B}_{12}$ supplements (Table 3). Blood $25(\mathrm{OH}) \mathrm{D}$ level was lower in the $50-90 \%$ organic group; after adjustment, this was observed in the $>90 \%$ organic group as well ( $P$ trend over categories $<0 \cdot 001$ ).

After adjusting for the healthy diet indicators (components 'alternative/vegetarian' and 'fast food' from principal component analysis), the differences and their statistical significance were retained in the cases of $25(\mathrm{OH}) \mathrm{D}, 15: 0$ and VA. However, in the cases of homocysteine, LDL cholesterol, EA, LA, ALA, AA and EA:VA, the differences were attenuated and lost significance, indicating that the association between these blood markers and organic intake was at least partly due to differences in food pattern. Interestingly, the 'fast food' component was solely responsible for the attenuation of the differences between homocysteine in the organic groups, whereas in the other cases both components played a role (data not shown).

\section{Discussion}

Consumption of organic food was associated with a more favourable pre-pregnancy BMI, lower prevalence of overweight and obesity before pregnancy and a lower prevalence of diabetes in pregnancy. Moreover, several differences concerning blood biomarkers were observed. We previously found ${ }^{(9)}$ that women consuming organic food during pregnancy had a food intake pattern comprising more products of vegetable origin - soya/ vegetarian products, vegetables, cereal and cereal products, bread, fruits, legumes - and fewer animal products - milk and milk products, meat and meat products - than women consuming conventional diets. A principal component analysis performed on the consumed food items confirmed these results. Most interestingly, scores corresponding to the first two main components found, 'alternative/vegetarian' and 'fast food', were markedly higher and lower, respectively, in the organic groups in comparison with the conventional (reference) group. Differences in food patterns are likely to have translated into differences in nutrient intakes among groups which, in time, could possibly contribute to the differences in blood biomarkers and health-related outcomes found in the present study.

\section{Study strengths and limitations}

Twenty-eight per cent of the participants considered in the present analysis were actively recruited using channels that are likely to address persons with alternative lifestyles (alternative lifestyles recruitment group). This was done to provide a deeper insight into the characteristics of this specific part of the population and to increase contrast in related exposure variables such as nutrition. Furthermore, this allowed us to compare a wide range of users of organic products, ranging from occasional users to very consistent users, which enabled our previous work on food patterns and intake ${ }^{(9)}$. The enrichment of the cohort with participants with alternative lifestyles may have led to some overestimation of the differences found between some organic groups and the conventional group. Nevertheless, the clear differences observed between the group of participants with only moderate consumption of organic foods $(<50 \%)$ and the conventional (reference) group indicates a considerable generalizability of our observations. Moreover, in our previous $\operatorname{work}^{(9)}$, we demonstrated that almost a third (29\%) of the participants from the general population recruitment group consumed at least some food of organic origin. This shows that a significant portion of the general population used organic food products at the time of the study, indicating a high applicability of the present results. Further strengths of the present work comprise the high number of participants and the very detailed FFQ.

A limitation of the present study concerns the different time points of the assessment of diet patterns (pregnancy week 34) and health-related characteristics (mostly in pregnancy week 30). The BMI value used in the present analysis is calculated based on the weight before pregnancy. Whereas this enables a BMI comparison between the groups, the value of the comparison depends on the assumption that intake of organic food during pregnancy was comparable to that before pregnancy. Concerning the women who consumed organic food before pregnancy, it is unlikely that they stopped this upon knowing that they were pregnant. In contrast, it is conceivable that some women who did not consume organic products before pregnancy would have started to do so afterwards. However, this would have led to an underestimation of the differences between the participants from the organic group and those of the conventional group. An additional limitation is that no information on physical activity was available and therefore explanations of differences related to energy intake/expenditure are only speculative.

\section{BMI, hypertension and diabetes in pregnancy}

Although we lack data on energy expenditure and therefore cannot be sure that the differences in pre-pregnancy BMI between the groups are due to diet, a lower BMI in the organic groups would fit with the consumption of less products from animal origin and more from plant origin ${ }^{(9)}$. These factors are known to be associated with a decreased risk for cardiovascular events, diabetes and all-cause mortality ${ }^{(18)}$. Strong inverse associations between dietary fibre intake and the cardiovascular risk factors excessive weight gain, central adiposity, high TAG, low HDL 
Table 3 Plasma levels of various biomarkers in pregnant women with varying purchases of food of organic v. conventional origin, KOALA Birth Cohort Study, The Netherlands, 2000-2002 (n 1339)

\begin{tabular}{|c|c|c|c|c|c|c|c|c|c|}
\hline \multirow[b]{2}{*}{ Biomarker } & \multicolumn{2}{|c|}{$\begin{array}{c}\text { Conventional (reference) } \\
(n \text { 767) }\end{array}$} & \multicolumn{2}{|c|}{$\begin{array}{c}<50 \% \text { organic } \\
(n 441)\end{array}$} & \multicolumn{2}{|c|}{$\begin{array}{c}50-90 \% \text { organic } \\
(n 73)\end{array}$} & \multicolumn{2}{|c|}{$\begin{array}{c}>90 \% \text { organic } \\
(n 58)\end{array}$} & \multirow{2}{*}{$\begin{array}{c}\text { Trend } \\
P\end{array}$} \\
\hline & Mean & SD & $B$ & $95 \% \mathrm{Cl}$ & $B$ & $95 \% \mathrm{Cl}$ & $B$ & $95 \% \mathrm{Cl}$ & \\
\hline \multicolumn{10}{|c|}{ TAG (mmol/l) } \\
\hline $\begin{array}{l}\text { Crude } \\
\text { Adjusted }\end{array}$ & 3.20 & 1.011 & $\begin{array}{l}-0.114 \\
-0.108\end{array}$ & $\begin{array}{l}-0.232,0.003 \\
-0.226,0.011\end{array}$ & $\begin{array}{l}-0.126 \\
-0.132\end{array}$ & $\begin{array}{l}-0.366,0.114 \\
-0.374,0.110\end{array}$ & $\begin{array}{l}-0.064 \\
-0.087\end{array}$ & $\begin{array}{l}-0.333,0.205 \\
-0.358,0.185\end{array}$ & $\begin{array}{l}0.125 \\
0.111\end{array}$ \\
\hline \multicolumn{10}{|c|}{ Total cholesterol (mmol/l) } \\
\hline $\begin{array}{l}\text { Crude } \\
\text { Adjusted }\end{array}$ & $6 \cdot 97$ & $1 \cdot 307$ & $\begin{array}{l}0.016 \\
0.002\end{array}$ & $\begin{array}{l}-0.142,0.173 \\
-0.157,0.161\end{array}$ & $\begin{array}{l}0.158 \\
0.138\end{array}$ & $\begin{array}{l}-0.165,0.481 \\
-0.188,0.465\end{array}$ & $\begin{array}{l}0.349 \\
0.319\end{array}$ & $\begin{array}{l}-0.010,0.709 \\
-0.045,0.682\end{array}$ & $\begin{array}{l}0.074 \\
0.128\end{array}$ \\
\hline \multicolumn{10}{|c|}{ HDL cholesterol (mmol/l) } \\
\hline $\begin{array}{l}\text { Crude } \\
\text { Adjusted }\end{array}$ & 1.76 & 0.446 & $\begin{array}{l}-0.038 \\
-0.044\end{array}$ & $\begin{array}{l}-0.090,0.013 \\
-0.143,0.087\end{array}$ & $\begin{array}{l}-0.042 \\
-0.076\end{array}$ & $\begin{array}{l}-0.147,0.064 \\
-0.312,0.120\end{array}$ & $\begin{array}{l}-0.046 \\
-0.043\end{array}$ & $\begin{array}{l}-0.163,0.072 \\
-0.220,0.306\end{array}$ & $\begin{array}{l}0.152 \\
0 \cdot 100\end{array}$ \\
\hline $\begin{array}{l}\text { LDL cholest } \\
\text { Crude } \\
\text { Adjusted }\end{array}$ & 3.76 & 1.229 & $\begin{array}{l}0.108 \\
0.098\end{array}$ & $\begin{array}{l}-0.041,0.257 \\
-0.052,0.248\end{array}$ & $\begin{array}{l}0.255 \\
0.236\end{array}$ & $\begin{array}{l}-0.050,0.559 \\
-0.071,0.543\end{array}$ & $\begin{array}{l}0.412 \\
0.404\end{array}$ & $\begin{array}{l}0.071,0.753 \\
0.059,0.749\end{array}$ & $\begin{array}{l}0.004 \\
0.007 \ddagger\end{array}$ \\
\hline \multicolumn{10}{|c|}{ 15: 0 (pentadecanoic acid; wt\%) $\dagger$} \\
\hline $\begin{array}{c}\text { Crude } \\
\text { Adjusted } \\
18: 1 n-9 \text { cis }\end{array}$ & 0.25 & 0.056 & $\begin{array}{l}0.035 \\
0.033\end{array}$ & $\begin{array}{l}0.028,0.042 \\
0.026,0.040\end{array}$ & $\begin{array}{l}0.055 \\
0.050\end{array}$ & $\begin{array}{l}0.040,0.069 \\
0.035,0.064\end{array}$ & $\begin{array}{l}0.046 \\
0.039\end{array}$ & $\begin{array}{l}0.030,0.062 \\
0.023,0.055\end{array}$ & $\begin{array}{l}<0.001 \\
<0.001\end{array}$ \\
\hline $\begin{array}{c}\text { 18: } 1 n-9, \text { cis } \\
\text { Crude } \\
\text { Adjusted }\end{array}$ & $9 \cdot 38$ & 1.073 & $\begin{array}{l}0.104 \\
0.121\end{array}$ & $\begin{array}{l}-0.022,0.230 \\
-0.006,0.247\end{array}$ & $\begin{array}{l}-0.262 \\
-0.217\end{array}$ & $\begin{array}{l}-0.521,-0.004 \\
-0.478,0.043\end{array}$ & $\begin{array}{l}0.021 \\
0.058\end{array}$ & $\begin{array}{l}-0.266,0.309 \\
-0.232,0.348\end{array}$ & $\begin{array}{l}0.880 \\
0.782\end{array}$ \\
\hline \multicolumn{10}{|c|}{$18: 1 n-9$, trans $(\mathrm{EA} ; \mathrm{wt} \%)^{*}$} \\
\hline $\begin{array}{c}\text { Crude } \\
\text { Adjusted } \\
18: 1 n-7, \text { trar }\end{array}$ & 0.404 & 0.2539 & $\begin{array}{l}-0.051 \\
-0.045\end{array}$ & $\begin{array}{l}-0.077,-0.026 \\
-0.070,-0.019\end{array}$ & $\begin{array}{l}-0.066 \\
-0.051\end{array}$ & $\begin{array}{l}-0.118,-0.014 \\
-0.103,0.002\end{array}$ & $\begin{array}{l}-0.100 \\
-0.081\end{array}$ & $\begin{array}{l}-0.158,-0.043 \\
-0.139,-0.023\end{array}$ & $\begin{array}{l}<0.001 \\
<0.001 \ddagger\end{array}$ \\
\hline $\begin{array}{c}\text { 18: } 1 n-7, \text { trar } \\
\text { Crude } \\
\text { Adjusted }\end{array}$ & $0 \cdot 185$ & 0.0630 & $\begin{array}{l}0.007 \\
0.004\end{array}$ & $\begin{array}{l}-0.001,0.015 \\
-0.004,0.011\end{array}$ & $\begin{array}{l}0.026 \\
0.022\end{array}$ & $\begin{array}{l}0.010,0.043 \\
0.007,0.038\end{array}$ & $\begin{array}{l}0.037 \\
0.031\end{array}$ & $\begin{array}{l}0.019,0.055 \\
0.013,0.048\end{array}$ & $\begin{array}{l}<0.001 \\
<0.001\end{array}$ \\
\hline \multicolumn{10}{|c|}{$18: 2 n-6$, cis $(\mathrm{LA} ; \mathrm{wt} \%)^{*}$} \\
\hline $\begin{array}{c}\text { Crude } \\
\text { Adjusted } \\
18: 2 n-7, \text { trar }\end{array}$ & $20 \cdot 84$ & $2 \cdot 210$ & $\begin{array}{l}0.219 \\
0.186\end{array}$ & $\begin{array}{l}-0.047,0.485 \\
-0.080,0.452\end{array}$ & $\begin{array}{l}1 \cdot 027 \\
0.926\end{array}$ & $\begin{array}{l}0.483,1.572 \\
0.381,1.476\end{array}$ & $\begin{array}{l}0.746 \\
0.695\end{array}$ & $\begin{array}{l}0.140,1.351 \\
0.086,1.305\end{array}$ & $\begin{array}{l}<0.001 \\
0.001 \ddagger\end{array}$ \\
\hline $\begin{array}{c}18: 2 n-7, \text { trar } \\
\text { Crude } \\
\text { Adjusted }\end{array}$ & 0.034 & 0.0229 & $\begin{array}{l}0.006 \\
0.006\end{array}$ & $\begin{array}{l}0.003,0.009 \\
0.003,0.009\end{array}$ & $\begin{array}{l}0.003 \\
0.003\end{array}$ & $\begin{array}{l}-0.003,0.009 \\
-0.003,0.009\end{array}$ & $\begin{array}{l}0.005 \\
0.006\end{array}$ & $\begin{array}{l}-0.002,0.012 \\
-0.001,0.013\end{array}$ & $\begin{array}{l}0.006 \\
0.001 \ddagger\end{array}$ \\
\hline \multicolumn{10}{|c|}{$18: 3 n-3(\text { ALA; } w t \%)^{*}$} \\
\hline $\begin{array}{c}\text { Crude } \\
\text { Adjusted } \\
20: 3 n-6 \text { (wt }\end{array}$ & 0.280 & $0 \cdot 0872$ & $\begin{array}{l}-0.002 \\
-0.001\end{array}$ & $\begin{array}{l}-0.013,0.008 \\
-0.012,0.009\end{array}$ & $\begin{array}{l}-0.017 \\
-0.016\end{array}$ & $\begin{array}{l}-0.038,0.004 \\
-0.035,0.008\end{array}$ & $\begin{array}{l}-0.029 \\
-0.027\end{array}$ & $\begin{array}{l}-0.052,-0.005 \\
-0.051,-0.003\end{array}$ & $\begin{array}{l}0.014 \\
0.035 \ddagger\end{array}$ \\
\hline $\begin{array}{l}\text { Crude } \\
\text { Adjusted }\end{array}$ & 3.41 & 0.587 & $\begin{array}{l}0.006 \\
0.016\end{array}$ & $\begin{array}{l}-0.063,0.075 \\
-0.053,0.086\end{array}$ & $\begin{array}{l}0.009 \\
0.034\end{array}$ & $\begin{array}{l}-0.133,0.150 \\
-0.109,0.177\end{array}$ & $\begin{array}{r}-0.009 \\
0.015\end{array}$ & $\begin{array}{l}-0.167,0.148 \\
-0.144,0.179\end{array}$ & $\begin{array}{l}0.965 \\
0.612\end{array}$ \\
\hline \multicolumn{10}{|c|}{$20: 4 n-6(A A ; w t \%)^{*}$} \\
\hline $\begin{array}{c}\text { Crude } \\
\text { Adjusted } \\
20: 5 n-3 \text { (EF }\end{array}$ & $7 \cdot 72$ & $1 \cdot 275$ & $\begin{array}{l}-0.409 \\
-0.405\end{array}$ & $\begin{array}{l}-0.557,-0.262 \\
-0.553,-0.257\end{array}$ & $\begin{array}{l}-0.565 \\
-0.573\end{array}$ & $\begin{array}{l}-0.867,-0.262 \\
-0.877,-0.270\end{array}$ & $\begin{array}{l}-0.387 \\
-0.340\end{array}$ & $\begin{array}{l}-0.723,-0.051 \\
-0.678,-0.002\end{array}$ & $\begin{array}{l}<0.001 \\
<0.001 \ddagger\end{array}$ \\
\hline $\begin{array}{l}\text { Crude } \\
\text { Adjusted }\end{array}$ & 0.424 & 0.2764 & $\begin{array}{l}0.010 \\
0.006\end{array}$ & $\begin{array}{l}-0.024,0.044 \\
-0.028,0.040\end{array}$ & $\begin{array}{l}0.009 \\
0.005\end{array}$ & $\begin{array}{l}-0.061,0.078 \\
-0.065,0.074\end{array}$ & $\begin{array}{l}-0.006 \\
-0.025\end{array}$ & $\begin{array}{l}-0.083,0.071 \\
-0.102,0.053\end{array}$ & $\begin{array}{l}0.811 \\
0.832\end{array}$ \\
\hline \multicolumn{10}{|c|}{$22: 4 n-6(w t \%)^{*}$} \\
\hline $\begin{array}{l}\text { Crude } \\
\text { Adjusted }\end{array}$ & 0.390 & 0.0966 & $\begin{array}{l}0.003 \\
0.005\end{array}$ & $\begin{array}{l}-0.009,0.014 \\
-0.007,0.016\end{array}$ & $\begin{array}{l}-0.005 \\
-0.001\end{array}$ & $\begin{array}{l}-0.029,0.018 \\
-0.025,0.022\end{array}$ & $\begin{array}{r}<0.001 \\
0.008\end{array}$ & $\begin{array}{l}-0.026,0.026 \\
-0.018,0.037\end{array}$ & $\begin{array}{l}0.987 \\
0.486\end{array}$ \\
\hline
\end{tabular}


Table 3 Continued

\begin{tabular}{|c|c|c|c|c|c|c|c|c|c|}
\hline \multirow[b]{2}{*}{ Biomarker } & \multicolumn{2}{|c|}{$\begin{array}{l}\text { Conventional (reference) } \\
\qquad(n \text { 767) }\end{array}$} & \multicolumn{2}{|c|}{$\begin{array}{c}<50 \% \text { organic } \\
(n 441)\end{array}$} & \multicolumn{2}{|c|}{$\begin{array}{c}50-90 \% \text { organic } \\
(n 73)\end{array}$} & \multicolumn{2}{|c|}{$\begin{array}{l}>90 \% \text { organic } \\
(n 58)\end{array}$} & \multirow{2}{*}{$\begin{array}{c}\text { Trend } \\
P\end{array}$} \\
\hline & Mean & SD & $B$ & $95 \% \mathrm{Cl}$ & $B$ & $95 \% \mathrm{Cl}$ & $B$ & $95 \% \mathrm{Cl}$ & \\
\hline \multicolumn{10}{|c|}{$22: 5 n-3(w t \%)^{*}$} \\
\hline $\begin{array}{l}\text { Crude } \\
\text { Adjusted }\end{array}$ & 0.535 & 0.1204 & $\begin{array}{l}-0.002 \\
-0.002\end{array}$ & $\begin{array}{l}-0.017,0.014 \\
-0.017,0.013\end{array}$ & $\begin{array}{l}-0.022 \\
-0.021\end{array}$ & $\begin{array}{l}-0.054,0.009 \\
-0.053,0.010\end{array}$ & $\begin{array}{l}-0.020 \\
-0.025\end{array}$ & $\begin{array}{l}-0.055,0.015 \\
-0.060,0.010\end{array}$ & $\begin{array}{l}0.143 \\
0.110\end{array}$ \\
\hline \multicolumn{10}{|c|}{$22: 6 n-3$ (DHA; wt\%)* } \\
\hline $\begin{array}{l}\text { Crude } \\
\text { Adjusted }\end{array}$ & 3.91 & 0.837 & $\begin{array}{l}-0.068 \\
-0.079\end{array}$ & $\begin{array}{l}-0.169,0.033 \\
-0.179,0.021\end{array}$ & $\begin{array}{l}-0.141 \\
-0.146\end{array}$ & $\begin{array}{l}-0.348,0.065 \\
-0.351,0.059\end{array}$ & $\begin{array}{l}-0.104 \\
-0.173\end{array}$ & $\begin{array}{l}-0.334,0.126 \\
-0.401,0.053\end{array}$ & $\begin{array}{l}0.086 \\
0.027\end{array}$ \\
\hline \multicolumn{10}{|c|}{ 18:1 n-9,trans:18: $1 n-7$, trans (EA:VA; wt $\% / w t \%)^{*}$} \\
\hline $\begin{array}{l}\text { Crude } \\
\text { Adjusted }\end{array}$ & $2 \cdot 30$ & $1 \cdot 318$ & $\begin{array}{l}-0.23 \\
-0.15\end{array}$ & $\begin{array}{l}-0.400,-0.064 \\
-0.321,0.013\end{array}$ & $\begin{array}{l}-0.52 \\
-0.37\end{array}$ & $\begin{array}{l}-0.860,-0.170 \\
-0.716,-0.031\end{array}$ & $\begin{array}{l}-0.66 \\
-0.49\end{array}$ & $\begin{array}{l}-1.039,-0.272 \\
-0.866,-0.103\end{array}$ & $\begin{array}{l}<0.001 \\
0.001 \ddagger\end{array}$ \\
\hline \multicolumn{10}{|c|}{ Ferritin† (ln, ng/ml) } \\
\hline $\begin{array}{l}\text { Crude } \\
\text { Adjusted }\end{array}$ & $2 \cdot 37$ & 0.966 & $\begin{array}{l}-0.016 \\
-0.028\end{array}$ & $\begin{array}{l}-0.131,0.100 \\
-0.143,0.087\end{array}$ & $\begin{array}{l}-0.088 \\
-0.076\end{array}$ & $\begin{array}{l}-0.321,0.151 \\
-0.312,0.160\end{array}$ & $\begin{array}{l}0.087 \\
0.043\end{array}$ & $\begin{array}{l}-0.176,0.350 \\
-0.220,0.306\end{array}$ & $\begin{array}{l}0.999 \\
0.804\end{array}$ \\
\hline \multicolumn{10}{|c|}{ Homocysteine $(\mu \mathrm{mol} / \mathrm{l})$} \\
\hline $\begin{array}{l}\text { Crude } \\
\text { Adjusted }\end{array}$ & $9 \cdot 35$ & 3.791 & $\begin{array}{l}-0.465 \\
-0.267\end{array}$ & $\begin{array}{l}-0.902,-0.028 \\
-0.706,-0.173\end{array}$ & $\begin{array}{l}-1.086 \\
-0.843\end{array}$ & $\begin{array}{l}-1.981,-0.190 \\
-1.740,-0.055\end{array}$ & $\begin{array}{l}-0.763 \\
-0.454\end{array}$ & $\begin{array}{l}-1.759,0.232 \\
-1.453,0.545\end{array}$ & $\begin{array}{l}0.004 \\
0.064\end{array}$ \\
\hline \multicolumn{10}{|c|}{ 25(OH)D (nmol/l) } \\
\hline $\begin{array}{l}\text { Crude } \\
\text { Adjusted }\end{array}$ & $44 \cdot 4$ & $18 \cdot 15$ & $\begin{array}{l}-0.370 \\
-0.140\end{array}$ & $\begin{array}{l}-2.502,1.762 \\
-3.266,0.465\end{array}$ & $\begin{array}{l}-5 \cdot 233 \\
-4 \cdot 638\end{array}$ & $\begin{array}{l}-9.599,-0.868 \\
-8.457,-0.818\end{array}$ & $\begin{array}{l}-4 \cdot 331 \\
-6 \cdot 433\end{array}$ & $\begin{array}{c}-9.185,0.522 \\
-10.681,-2.185\end{array}$ & $\begin{array}{r}0.019 \\
<0.001\end{array}$ \\
\hline
\end{tabular}

$\mathrm{OA}$, oleic acid; EA, elaidic acid; VA, vaccenic acid; LA, linoleic acid; RA, rumenic acid; ALA a-linolenic acid; AA, arachidonic acid; 25(OH)D, 25-hydroxyvitamin D; CLA, conjugated linoleic acids (18:2 conjugated isomers). Data are presented as mean and SD in the conventional (reference) group and as mean difference values and $95 \% \mathrm{Cl}$ in the three organic groups. Fatty acids are expressed as percentage of total blood fatty acids. Significant results $(P<0.05$ or $\mathrm{Cl}$ not including the null value, which is equivalent to $P<0.05)$ are shown in bold font.

Unadjusted values are crude $B$; adjusted values controlled for the following covariates. Total cholesterol. HDL cholesterol, LDL cholesterol and TAG: maternal age, parity (numerical), alcohol consumption (numerical) and smoking (numerical). Single fatty acids (except VA, CLA and EA.VA), homocysteine and vitamin E. maternal age and parity (numerical); since only a few participants took fatty acids supplements ( 7 in the conventional group, $n 6$ in the $<50 \%$ oranic and $n 1$ in the $>90 \%$ organic group), the were not considered as covariates. Ferritin (logarithmic): maternal age, parity (numerical) and Fe supplements (as dummies). Homocysteine: maternal age, parity (numerical) and vitamin $\mathrm{B}_{12}$ supplements. $25(\mathrm{OH}) \mathrm{D}$ : maternal age, parity (numerical), season (as dummies) and vitamin D supplements (as dummies). Ruminant fatty acids (VA, CLA and EA:VA): maternal age, parity (numerical) and season (as dummies).

Data were missing as follows. For conventional group: total cholesterol and homocysteine, $n$ 1; 25(OH)D, $n$ 2; HDL cholesterol, $n 3$; TAG, $n 4$; RA, $n 90$. For $<50 \%$ organic group: $25(\mathrm{OH}) \mathrm{D}$ and TAG, $n$ 1; RA, $n 45$. For $50-90 \%$ organic group, $n$ 5. For $>90 \%$ organic group: RA, $n 6$.

*Weight percentage of total fatty acids in plasma phospholipids.

fFerritin concentration in the conventional (reference) group was 15.9 (SD 17.85) $\mathrm{ng} / \mathrm{ml}$. Since this variable had a markedly skewed distribution, the natural logarithm was calculated and shown in the table.

fLost significance when healthy diet indicators were added to the adjusted model. 
cholesterol, high LDC cholesterol and elevated blood pressure have been shown ${ }^{(18)}$.

In the present study, no linear trend for a different prevalence of hypertension during pregnancy was observed over the organic groups, but the $50-90 \%$ organic group showed a lower prevalence than the other groups. In recent meta-analyses of associations between food intake and hypertensive disorders in pregnancy, the authors came to the conclusion that lower $\mathrm{Mg}$ and $\mathrm{Ca}$ intake measured during pregnancy might be associated with hypertension ${ }^{(20,21)}$. We showed that the intake of these micronutrients was higher in the organic groups ${ }^{(9)}$. The lower prevalence of pregnancy diabetes in the organic groups is in line with the lower BMI and several diet characteristics. Since diabetes in pregnancy is usually diagnosed around 26 week of pregnancy and, upon diagnosis, intensive dietetic counselling is likely to occur, a sensitivity analysis was performed to find out whether this diagnosis could have affected the diet. When excluding women with pregnancy diabetes from the analysis, the results remained unchanged (data not shown).

\section{Blood lipids and fatty acids}

In this section and below, we focus on blood biomarkers that differed by at least $10 \%$ in one or more of the organic groups relative to the conventional (reference group) and relate these to our previously reported differences in food and nutrient intake ${ }^{(9)}$ (see Table 4).

Blood lipid analyses showed statistically significant higher levels of LDL cholesterol in the organic groups, the difference between the $>90 \%$ group and the conventional (reference) group being $11 \%$, with a significant test for trend (Table 4). The reason for these higher levels in the organic groups is unclear. The SFA 15:0 is considered to be a marker of dairy intake since its main dietary source is cows' milk butterfat ${ }^{(22)} .15$ : 0 was found to be higher in the organic groups (Table 4), consistent with the higher intake of cheese ${ }^{(9)}$ and of whole-milk products including butter (data not shown). The lower blood levels of ALA are surprising, since the usual sources of this fatty acid would be expected to play a relatively bigger role in the organic nutrition. Our previous food intake analysis, however, did not confirm higher intakes of seeds, nuts and oils in the organic groups ${ }^{(9)}$. Although the ALA intake in the 50-90\% and $>90 \%$ organic groups was numerically lower than in the reference group, the differences did not reach statistical significance.

We used EA:VA as a marker of industrial $v$. natural trans-fatty acid intake. Industrial trans-fatty acids originate from partially hydrogenated vegetable oils (industrially hardened fats; e.g. EA) whereas natural trans-fatty acids are derived mainly from ruminant fat intake (dairy, ruminant meat; mainly VA and RA). The lower plasma EA:VA ratio observed in the organic groups is consistent with the lower EA:VA observed in breast milk from women consuming organic products ${ }^{(4,23)}$, and with the higher VA intake and lower EA intake observed in the organic groups compared with the conventional (reference) group ${ }^{(9)}$. The lower EA:VA intake in the organic groups is probably related to the higher intake of cheese and takes place even though the food pattern of the organic groups comprises lower amounts of other milk products and meat ${ }^{(9)}$. In face of these results, we conducted a new, single-item analysis of butter and margarine intake in the various groups to investigate whether there was a preference for a certain type of fat in the various groups. In the organic groups, there was a higher intake of butter and a lower intake of margarine relative to the conventional (reference) group (data not shown).

Finally, organic milk products and meat were shown to be particularly rich in $\mathrm{RA}$ and $\mathrm{VA}^{(24-26)}$. A recent metaanalysis confirmed the higher levels of CLA (18:2 conjugated isomers) in organic milk and indicated that the higher grazing/conserved forage intakes were the main reason for the observed differences between organic and

Table 4 Point-by-point comparison between the main differences* in biomarker plasma values detected in the present work in the organic groups $v$. the conventional (reference) group and previously observed tendencies in the corresponding micronutrient and food intake ${ }^{(9)}$, KOALA Birth Cohort Study, The Netherlands, 2000-2002 ( $n$ 1339)

\begin{tabular}{|c|c|c|c|}
\hline & $\begin{array}{l}\text { Blood level in } \\
\text { organic groups } v \text {. } \\
\text { conventional }\end{array}$ & $\begin{array}{l}\text { Micronutrient intake } \\
\text { in organic groups } v \text {. } \\
\text { conventional }\end{array}$ & Food intake in organic groups $v$. conventional \\
\hline 15:0 (pentadecanoic acid) & $\uparrow$ & $15: 0 \uparrow$ & Cheese $\uparrow$ (even though total milk and milk products $\downarrow$ ) \\
\hline $18: 2 n-7$, trans, $n-9$, cis (RA) & $\uparrow \uparrow$ & Total CLA $\uparrow$ & Cheese $\uparrow$ (even though total milk and milk products $\downarrow$ ) \\
\hline $18: 3 n-3(\mathrm{ALA})$ & $\downarrow \dagger$ & ALA $\leftrightarrow$ & - \\
\hline $18: 1 n-9$, trans $(\mathrm{EA})$ & $\downarrow \dagger$ & $\mathrm{EA} \downarrow$ & Fast food $\downarrow$ \\
\hline $18: 1 n-7$, trans (VA) & $\uparrow$ & $\mathrm{VA} \uparrow$ & Cheese $\uparrow$ (even though total milk and milk products $\downarrow$ ) \\
\hline $\begin{array}{l}\text { 18: } 1 n-9, \text { trans: } 18: 1 n-7 \\
\quad \text { trans (EA:VA) }\end{array}$ & $\downarrow \dagger$ & $E A: V A \downarrow$ & $\begin{array}{l}\text { Fast food } \downarrow \\
\text { Cheese } \uparrow \text { (even though total milk and milk products } \downarrow \text { ) }\end{array}$ \\
\hline Homocysteine $(\mu \mathrm{mol} / \mathrm{l})$ & $\downarrow \dagger$ & Folate $\uparrow$ & Vegetable products $\uparrow$ \\
\hline $25(\mathrm{OH}) \mathrm{D}(\mathrm{nmol} / \mathrm{l})$ & $\downarrow$ & Vitamin $D \downarrow$ & Meat, fish and total milk products $\downarrow$ \\
\hline
\end{tabular}

RA, rumenic acid; ALA a-linolenic acid; EA, elaidic acid; VA, vaccenic acid; 25(OH)D, 25-hydroxyvitamin D; $\uparrow$, increased; $\downarrow$, decreased; CLA, conjugated linoleic acids (18:2 conjugated isomers); $\leftrightarrow$, no difference.

${ }^{*}$ That is, trend is statistically significant and consistent over the three organic groups and difference corresponds to at least $10 \%$ of the reference value in at least one organic group, either in the crude or in the main adjusted model.

†Adjustment for healthy diet indicators (components 'alternative/vegetarian' and 'fast food' from principal component analysis) attenuated the differences. 
conventional milk ${ }^{(26)}$. Therefore, and since the differences between the organic groups and the conventional (reference) group were not attenuated by adjusting for the healthy diet indicators (components 'alternative/ vegetarian' and 'fast food' from principal components analysis), it is conceivable that the origin of milk products and meat has contributed to the higher plasma levels of VA in the organic groups.

\section{Other blood biomarkers}

The blood ferritin values were only slightly lower in the organic groups than in the reference group (ln of the concentration in $\mathrm{ng} / \mathrm{ml}$ at most 0.088 lower than the mean value of 2.37 in the reference group; therefore not shown in Table 4). In the organic groups, intake of haem Fe was markedly lower than in the conventional group, the opposite happening with non-haem $\mathrm{Fe}^{(9)}$. Taken together, this indicates that the well-known different absorption of the two types of Fe - haem and non-haem - is being somehow compensated for.

The amounts of dietary folate ingested in the organic groups were higher than in the conventional group (between 288 and $300 \mu \mathrm{g} / \mathrm{d}$ in the organic groups, $265 \mu \mathrm{g} / \mathrm{d}$ in the conventional group) and close to the daily requirements for adult women (about $300 \mu \mathrm{g} / \mathrm{d}$ ). The lower blood values of homocysteine detected in the organic groups could be explained by the higher intake of dietary folate. On the contrary, the somewhat lower levels of ingested vitamin $B_{12}$ in the organic groups did not result in higher homocysteine levels.

The lower blood levels of $25(\mathrm{OH}) \mathrm{D}$ in the organic groups are likely to be related to the lower amounts of fish consumed, since fatty fish is an important source of vitamin D. In addition, the lower intake of milk products in the organic groups could have played a role as well, given that $\mathrm{Ca}$ is necessary for the dermal conversion from 7-dehydrocholesterol into 25(OH)D. These results are, however, difficult to interpret because information on sunlight exposure, a major trigger of 25(OH)D synthesis, is missing. Lower blood levels of $25(\mathrm{OH}) \mathrm{D}$ in the organic group were not compensated by higher use of vitamin D supplements ${ }^{(9)}$.

\section{Possible implications for health}

Overall, our results suggest that consumption of organic products has a positive impact on health, whereby the associated food intake pattern, rather than the organic products per se, is likely to play a prominent role. Especially in relation to the biomarkers RA, ALA, EA and homocysteine, a healthier diet pattern - defined by high scores of the 'alternative/vegetarian' component and low scores of the 'fast food' component - can be assumed responsible for the observed differences between organic groups and the conventional (reference) group, since adjusting for it attenuated the differences. In the cases in which no attenuation or loss of significance was observed, no conclusions can be drawn on the origin of the differences in biomarker levels between the groups; either the reason was not related to the food patterns or our approach to compensate for the effect of healthier food patterns was not powerful enough to correct for it.

The lower prevalence rates of overweight and obesity in the organic groups are particularly interesting, since overweight and obesity are known risk factors for an adverse pregnancy outcome ${ }^{(27,28)}$ and CVD in women ${ }^{(29)}$. Prepregnancy weight is one of the maternal characteristics significantly associated with newborn cardiometabolic traits ${ }^{(30)}$. Furthermore, in the full-term placenta, maternal obesity affects placental fatty acid uptake, which may modify the fetal metabolism ${ }^{(31)}$. Maternal overweight/obesity is therefore not only relevant for the woman's health, but also for the offspring's predisposition for diseases in later life.

The comparatively higher intake of trans-fatty acids derived from ruminant fat (i.e. mainly VA and RA) and the lower intake of trans-fatty acids from partially hydrogenated vegetable oils (marker EA) in the organic groups might have a long-term positive effect on the risk of CVD. Trans-fatty acids from partially hydrogenated vegetable oils can contribute to pathological situations, such as IHD $^{(32)}$ and type 2 diabetes $^{(33)}$. A meta-analysis of cohort studies comparing the effect of industrial $v$. ruminant trans-fatty acids on CHD suggested that ruminant transfatty acids had favourable effects ${ }^{(33)}$. Whether the plasma levels of the various trans-fatty acids are related to the observed differences in BMI, prevalence of overweight, obesity and gestational diabetes deserves further investigations. It is conceivable that the intake of trans-fatty acids from partially hydrogenated vegetable oils in the normal population is already lower than at the time participants were being recruited to participate in the KOALA study, since the European industry had just started lowering trans-fats in processed food products on a voluntary basis. In the Netherlands, the lowering of trans-fatty acids contents started in the 1990s with retail margarines and frying fats, and continued after 2000 with other consumer food products ${ }^{(35)}$.

Folate intake before conception is important for the offspring's health. The higher intake of folate in the organic groups during pregnancy ${ }^{(9)}$, together with the observed lower plasma levels of homocysteine, might be relevant, especially if one assumes that women who consume organic products during pregnancy are more likely to do so as well before becoming pregnant.

Due attention should be paid to the lower intake and blood levels of 25(OH)D in the organic groups in view of the importance of this vitamin for the growing embryo/ fetus. In principle, these lower levels could be due to a reduced adherence to taking vitamin D supplements and, in our previous work ${ }^{(9)}$, we observed different intakes of vitamin D supplements among the various groups. Whereas low-dose supplements were more often used in the organic groups, supplements according to the recommendation of taking $10 \mu \mathrm{g} / \mathrm{d}$ in pregnancy were consumed 
more seldom. Neither adjusting for vitamin D supplements (Table 3) nor for healthy diet indicators, however, diminished the statistical significance of the results on the blood levels of vitamin D. In addition to the vitamin D supplements issue, an interference of the season in which the participants of the various groups have been recruited is conceivable. It should however be noticed that adjusting for season did not attenuate the statistical significance of the results (Table 3). A tighter control of $25(\mathrm{OH}) \mathrm{D}$ status of pregnant women consuming organic products appears therefore advisable. However, with respect to possible consequences to the offspring, new observations suggest that the fetus might regulate $25(\mathrm{OH}) \mathrm{D}$ metabolites independently of the maternal blood level of $25(\mathrm{OH}) \mathrm{D}^{(36)}$.

Nowadays, a global transformation of traditional diets can be observed, in which the intake of meats, oils, refined fats and refined sugars is increasing. This transition goes handin-hand with various human health risks and low environmental sustainability, with the interplay among diet, health and environment becoming more and more apparent ${ }^{(37)}$. According to these authors, there are already plausible solutions to this diet-environment-health trilemma, namely alternative diets such as the Mediterranean, pescetarian and vegetarian diets. Should these diets be adopted by more people, this would positively affect both global environmental and public health ${ }^{(37)}$. The food pattern that we found to be associated with the consumption of organic food exhibits various similarities with these diets ${ }^{(9)}$ and might constitute an additional solution to improve human health and to increase environmental sustainability.

\section{Conclusions}

Our work shows that consumption of organic products during pregnancy is associated with more favourable prepregnancy BMI and lower prevalence of overweight and gestational diabetes. Further favourable aspects associated with the consumption of organic food are lower plasma level of a trans-fatty acid marker of industrially hydrogenated fats (EA) and higher plasma levels of markers of trans-fatty acids from natural origin, as well as lower plasma levels of homocysteine, which may be indicative of higher folate intake. Attention should be given to the relatively lower plasma levels of $25(\mathrm{OH}) \mathrm{D}$ of pregnant women consuming organic products.

Our results also give a clue on how specific food intake patterns associated with the consumption of organic products are likely to play a major role in the observed associations between the consumption of organic products and health-related outcomes.

\section{Acknowledgements}

Acknowledgements: Daniel Krüerke, $\mathrm{PhD}$, and Andreas Jäschke, $\mathrm{PhD}$, are gratefully acknowledged for facilitating the work on this project at the Clinic Arlesheim, Arlesheim, Switzerland. Financial support: The KOALA Birth Cohort Study was supported by a grant from the Netherlands Organization for Health Research and Development (ZonMw Prevention Program 1, grant number 2001-1-1260), the present analysis by the Christophorus Foundation (Stuttgart, Germany). The sponsors had no influence on the analysis and reporting of the results. Conflict of interest: None declared. Authorship: A.P.S.-W.: study design, statistical analysis and drafting of manuscript. C.M.-P.: management and quality control of data processing. E.H.J.M.J.: supervision of laboratory measurements (blood markers). M.C.J.M.v.D.: processing of data, advice on data analysis. P.C.D.: study design and data collection. C.T.: study design, coordination of data collection and supervision of statistical analysis. All authors reviewed the manuscript and agreed with the final version. Ethics of human subject participation: The KOALA Birth Cohort Study was approved by the Medical Ethical Committee of Maastricht University/ Academic Hospital Maastricht (MUMC+). All children's parents signed for written informed consent.

\section{References}

1. IFOAM Organics International (2008) What is organic agriculture? http://www.ifoam.bio/en/faq-organic-agriculture\#1 (accessed October 2016).

2. European Commission (2013) Sustainable Development in the European Union. Luxembourg: Publications Office of the European Union.

3. van de Vijver LP \& van Vliet ME (2012) Health effects of an organic diet - consumer experiences in the Netherlands. J Sci Food Agric 92, 2923-2927.

4. Rist L, Mueller A, Barthel C et al. (2007) Influence of organic diet on the amount of conjugated linoleic acids in breast milk of lactating women in the Netherlands. Br J Nutr $\mathbf{9 7}$, 735-743.

5. Thijs C, Muller A, Rist L et al. (2011) Fatty acids in breast milk and development of atopic eczema and allergic sensitisation in infancy. Allergy 66, 58-67.

6. Kummeling I, Thijs C, Huber M et al. (2008) Consumption of organic foods and risk of atopic disease during the first 2 years of life in the Netherlands. Br J Nutr 99, 598-605.

7. Torjusen H, Brantsaeter AL, Haugen M et al. (2014) Reduced risk of pre-eclampsia with organic vegetable consumption: results from the prospective Norwegian Mother and Child Cohort Study. BMJ Open 4, e006143.

8. Brantsaeter AL, Torjusen H, Meltzer HM et al. (2016) Organic food consumption during pregnancy and hypospadias and cryptorchidism at birth: the Norwegian Mother and Child Cohort Study (MoBa). Environ Health Perspect 124, 357-364.

9. Simões-Wüst AP, Moltó-Puigmartí C, van Dongen MCJM et al. (2017) Organic food consumption during pregnancy is associated with different consumer profiles, food patterns and intake: the KOALA Birth Cohort Study. Public Health Nutr (Epublication ahead of print version).

10. Torjusen H, Lieblein G, Naes T et al. (2012) Food patterns and dietary quality associated with organic food consumption during pregnancy; data from a large cohort of pregnant women in Norway. BMC Public Health 12, 612.

11. Kesse-Guyot E, Peneau S, Mejean C et al. (2013) Profiles of organic food consumers in a large sample of French adults: 
results from the Nutrinet-Sante cohort study. PLoS One $\mathbf{8}$, e76998.

12. Eisinger-Watzl M, Wittig F, Heuer T et al. (2015) Customers purchasing organic food - do they live healthier? Results of the German National Nutrition Survey II. Eur J Nutr Food Saf 5, 59-71.

13. Bastiaanssen JM, de Bie RA, Bastiaenen $\mathrm{CH}$ et al. (2005) Etiology and prognosis of pregnancy-related pelvic girdle pain; design of a longitudinal study. BMC Public Health 5, 1.

14. Kummeling I, Thijs C, Penders J et al. (2005) Etiology of atopy in infancy: the KOALA Birth Cohort Study. Pediatr Allergy Immunol 16, 679-684.

15. Grootenhuis PA, Westenbrink S, Sie CM et al. (1995) A semiquantitative food frequency questionnaire for use in epidemiologic research among the elderly: validation by comparison with dietary history. J Clin Epidemiol $\mathbf{4 8}$, 859-868.

16. Kraft J, Collomb M, Mockel P et al. (2003) Differences in CLA isomer distribution of cow's milk lipids. Lipids $\mathbf{3 8}$, 657-664.

17. Cremers E, Thijs C, Penders J et al. (2011) Maternal and child's vitamin D supplement use and vitamin D level in relation to childhood lung function: the KOALA Birth Cohort Study. Thorax 66, 474-480.

18. Colditz GA (2015) Healthy diet in adults. In UpToDate ${ }^{\circledR}[$ TO Lipman and L Park, editors]. https://www.uptodate.com/ contents/healthy-diet-in-adults (accessed January 2015).

19. Ludwig DS, Pereira MA, Kroenke CH et al. (1999) Dietary fiber, weight gain, and cardiovascular disease risk factors in young adults. JAMA 282, 1539-1546.

20. Schoenaker DA, Soedamah-Muthu SS \& Mishra GD (2014) The association between dietary factors and gestational hypertension and pre-eclampsia: a systematic review and meta-analysis of observational studies. BMC Med 12, 157.

21. He L, Lang L, Li Y et al. (2016) Comparison of serum zinc, calcium, and magnesium concentrations in women with pregnancy-induced hypertension and healthy pregnant women: a meta-analysis. Hypertens Pregnancy 35, 202-209.

22. Smedman AE, Gustafsson IB, Berglund LG et al. (1999) Pentadecanoic acid in serum as a marker for intake of milk fat: relations between intake of milk fat and metabolic risk factors. Am J Clin Nutr 69, 22-29.

23. Mueller A, Thijs C, Rist L et al. (2010) Trans fatty acids in human milk are an indicator of different maternal dietary sources containing trans fatty acids. Lipids 45, 245-251.

24. Jahreis G, Fritsche J \& Steinhart H (1997) Conjugated linoleic acid in milk fat: high variation depending on production system. Nutr Res 17, 1479-1484.

25. Bergamo P, Fedele E, Iannibelli L et al. (2003) Fat-soluble vitamin contents and fatty acid composition in organic and conventional Italian dairy products. Food Chem 82, 625-631.

26. Dannenberger D, Nuernberg G, Scollan N et al. (2004) Effect of diet on the deposition of $n-3$ fatty acids, conjugated linoleic and C18:1 trans fatty acid isomers in muscle lipids of German Holstein bulls. J Agric Food Chem 52, 6607-6615.

27. Ramsey PS, Patrick S \& Schenken RS (2017) Obesity in pregnancy: Complications and maternal management. In UpToDate $^{\circledR}$ [CJ Lockwood, F Pi-Sunyer and V Barss, editors]. https://www.uptodate.com/contents/obesity-inpregnancy-complications-and-maternal-management?source $=$ search_result $\&$ search $=$ The $\% 20$ impact $\% 20$ of $\% 20$ obesity $\% 20$ on\%20fertility\%20and\%20pregnancy\&selectedTitle=3 150 (accessed June 2017).

28. Lockwood C \& Magriples U (2017) Prenatal care: Initial assessment. In UpToDate ${ }^{\circledR}$ [S Ramin and V Barss, editors]. https://www.uptodate.com/contents/prenatal-care-initialassessment?source=search_result\&search $=$ The $\% 20$ initial $\%$ 20prenatal\%20assessment $\% 20$ and $\% 20$ patient $\% 20$ education \&selectedTitle=3 150 (accessed June 2017).

29. Douglas P \& Poppas A (2016) Overview of cardiovascular risk factors in women. In UpToDate ${ }^{\circledR}[\mathrm{J}$ Kaski and B Downey, editors]. https://www.uptodate.com/contents/ overview-of-cardiovascular-risk-factors-in-women?source= search_result\&search=Determinants $\% 20$ and $\% 20$ manage ment $\% 20$ of $\% 20$ cardiovascular\%20risk\%20in\%20women\& selectedTitle=1 150 (accessed June 2017).

30. Morrison KM, Anand SS, Yusuf S et al. (2013) Maternal and pregnancy related predictors of cardiometabolic traits in newborns. PLoS One 8, e 55815.

31. Dube E, Gravel A, Martin C et al. (2012) Modulation of fatty acid transport and metabolism by maternal obesity in the human full-term placenta. Biol Reprod 87, 14, 1-11.

32. Stender $S \&$ Dyerberg J (2004) Influence of trans fatty acids on health. Ann Nutr Metab 48, 61-66.

33. Odegaard A \& Pereira M (2006) Trans fatty acids, insulin resistance, and type 2 diabetes. Nutr Rev 64, 364-372.

34. Bendsen NT, Christensen R, Bartels EM et al. (2011) Consumption of industrial and ruminant trans fatty acids and risk of coronary heart disease: a systematic review and meta-analysis of cohort studies. Eur J Clin Nutr $\mathbf{6 5}$, 773-783.

35. Katan MB (2006) Regulation of trans fats: the gap, the Polder, and McDonald's French fries. Atheroscler Suppl 7, 63-66.

36. Hanson C, Anderson-Berry A, Lyden E et al. (2016) Dynamics of vitamin D metabolism in maternal-fetal dyads. J Pediatr Gastroenterol Nutr 62, 486-490.

37. Tilman D \& Clark M (2014) Global diets link environmental sustainability and human health. Nature 515, 518-522. 